Naturally occurring silicates of the metal are dealt with elsewhere, although the phase-rule diagram of the system $\mathrm{MgO}: \mathrm{SiO}_{2}$ is given and also full details of the physical properties of the anhydrous orthosilicate and the varieties of metasilicate, namely, clino-enstatite, enstatite, and the monoclinic and rhombic amphiboles. The phosphates present some rather formidable structural problems on account of their number and varicty.

It would be interesting to discover the orientation of the stable salt $\mathrm{Mg}_{3}\left(\mathrm{PO}_{4}\right)_{2} .22 \mathrm{H}_{2} \mathrm{O}$, which Bassett and Bedwell observed to change to the octahydrate, in presence of the mother-liquor, in the course of a few weeks. The work of these authorities on the glowing of orthophosphates and pyrophosphates might have been given in fuller detail, particularly their observations on the heat evolution on glowing and their co-ordination theory of the structural changes which accompany the glow. A structural formula has recently been assigned by Beintema from $\mathrm{X}$-ray analysis to magnesium antimonate $\mathrm{MgO} . \mathrm{Sb}_{2} \mathrm{O}_{5} \cdot 12 \mathrm{H}_{2} \mathrm{O}$, in which six molecules of water are co-ordinated with the cation and six hydroxyl groups with each of two anions, thus: $\left[\mathrm{MIg}\left(\mathrm{H}_{2} \mathrm{O}\right)_{6}\right]\left[\mathrm{Sb}(\mathrm{OH})_{6}\right]_{2}$.

\title{
CLIMATE AND MAN
}

\section{Klima, Wetter, Mensch}

Yon E. Brezina, W. Hellpach, R. Hesse, E. Martini, B. de Rudder, A. Schittenhelm, A. Seybold, L. Weickmann. Herausgegeben von Heinz Woltereck. Pp. viii +446 . (Leipzig: Quelle und Meyer, 1938.) 18 gold marks.

T'HE subject of this book is climate and weather as part of man's environment-Lebensraum in the literal sense-including not only the natural air of the free countryside, but also the modified air of great cities, houses, air-conditioned buildings and, on a still smaller scale, within clothing. These studies on the borderlands of meteorology and biology or medicine are highly specialized, and they are dealt with in a series of memoirs by different authorities. In the first and longest section, Prof. I. Weickmann sets out the fundamental basis, the elements of climate and weather. This is to some extent orthodox meteorology, but with a difference. It starts with a detailed account of solar radiations of all wave-lengths and their biological effects; other climatic elements in turn are treated from the same point of view. 'Sensible' temperature and the cooling power of air are fully discussed, while for humidity the important quantity is taken as the physiological saturation deficit.

The processes of weather come next; here the biological aspect is to some extent lost sight of, and the author is drawn aside into his favourite topic of rhythms in barometric pressure. This is followed by an account of seasonal and other long-period weather changes, and the section ends with a thorough and interesting account of the modern study of micro-climatology, the effect of small surface features-hills and valleys, streets, forests and growing crops. These minute studies have been pursued very thoroughly in Germany in recent years, and the book contains a great deal of information which is not otherwise readily available, as well as some striking illustrations.

In the rest of the book the emphasis is mainly on the biological aspect. B. de Rudder has an important memoir on the basis of human bioclimatics, divided into the influence of the separate climatic elements, of climate in general and of weather (meteorobiology). Solar radiation still holds pride of place, from such diverse aspects as rickets, sunburn, and the coincidence between outbreaks of cerebro-spinal meningitis and sunspot maxima. In questions of bioclimatics there are still plenty of unknown quantities. A. Schittenhelm deals with the curative factors of different types of climate, stressing the need for medical advice in selecting the correct treatment, for example, for nervous diseases. E. Martini describes the part played by climate in the causation of disease-a highly complex subject involving the life-history of the organisms responsible for epidemics such as malaria, which is treated at length. The remaining chapters, comparatively short, are: Man in an Artificial Climate (E. Brezina); Plants, Climate and Weather (A. Seybold); The Animal and the Climate (R. Hesse); and Culture and Climate, by W. Hellpach, a philosophical essay on 'culture', relating not only material civilization but also political development, religion and other spiritual values to the natural environment, of which climato is an important part.

The book is well printed, but in the Gothic type which he who runs (or travels by train) finds difficult to read. There are no exact references, merely citations of a few names; there is no bibliography and no author index, so that it is very difficult to follow up or find the authority for any particular statement. $\quad$ C. E. P. Brooks 